\title{
Letramento acadêmico de estudantes estrangeiros: múltiplos desafios, múltiplas estratégias
}

\author{
Academic literacy of foreign students: multiple challenges, multiple \\ strategies
}

\section{Literacidad academica de estudiantes extranjeros: múltiples desafíos, múltiples estratégias}

\author{
Paula Aparecida Diniz Gomides Castro Santos ${ }^{1}$ \\ Universidade Federal de Minas Gerais, Programa de Pós-Graduação em Educação, \\ Professora. \\ https://orcid.org/0000-0002-4699-4309 \\ Maria Do Socorro Alencar Nunes Macedo \\ Universidade Federal de São João Del Rey, Programa de Pós-Graduação em Educação, \\ Professora Titular, Pesquisadora do CNPq \\ https://orcid.org/0000-0003-3103-3203
}

Resumo: Analisamos, neste artigo estratégias desenvolvidas por estudantes estrangeiros para lidarem com as demandas do contexto acadêmico, em uma universidade pública brasileira. 0s dados analisados derivam do trabalho de Dissertação de Santos (2019) e foram colhidos no segundo semestre de 2017 na Universidade Federal de São João del Rei. A fundamentação teórico-metodológica está baseada nos Novos Estudos do Letramento e em contribuições da sociologia de Pierre Bourdieu. Foram realizadas 14 entrevistas semiestruturadas com estudantes de nove diferentes paises, matriculados em cursos de todas as áreas, exceto das ciências humanas. Os estudantes foram inquiridos sobre sua chegada ao Brasil, as atividades desenvolvidas na universidade e suas dificuldades nas disciplinas dos cursos aos quais estavam matriculados. As entrevistas foram gravadas e transcritas, com vistas a compreensão dos recursos mobilizados pelos estudantes para contornar tais possíveis dificuldades. Os resultados evidenciam a grande variedade de estratégias de estudo, dentre elas o pedido de auxilio a colegas brasileiros para o cumprimento das demandas dos cursos, a preferência pelo suporte impresso na leitura de textos acadêmicos, o uso de pesquisas na internet para ampliar vocabulário, a solicitação de auxilio aos professores e utilização de monitoria, oferecida pela universidade. 0 estudo conclui que

Mestre em Educação pela Universidade Federal de São João del-Rei; doutoranda em Educação pela Universidade Federal de Minas Gerais.

2 Pós-doutora pela University of London, King's College; Doutora e Mestre em Educação pela Universidade Federal de Minas Gerais. 
algumas dificuldades não se relacionam apenas à questão da fluência na língua portuguesa falada no Brasil, mas à pouca familiaridade com práticas de leitura e escrita próprias do campo acadêmico. Indicamos, ainda, a assimetria entre os paises do norte em relação ao Brasil, quando se trata da internacionalização da universidade.

Palavras-chave: Letramentos acadêmicos. Estudantes estrangeiros. Ensino superior. Escrita na universidade. Estratégias.

Abstract: In this article we analyze strategies developed by foreign students to deal with the demands of the academic context in a Brazilian public university. The data analyzed derive from the work of Dissertation of Santos (2019) and were collected in the second semester of 2017 at the Federal University of São João del Rei. The theoretical-methodological basis is based on New Literacy Studies and contributions from Pierre Bourdieu's sociology. Fourteen semi-structured interviews were conducted with students from nine different countries, enrolled in courses in all areas except the human sciences. The students were asked about their arrival in Brazil, the activities developed at the university and their difficulties in the subjects of the courses to which they were enrolled. The interviews were recorded and transcribed in order to understand the resources mobilized by the students to overcome these possible difficulties. The results show the great variety of study strategies, among them the request for help from Brazilian colleagues in meeting the demands of the courses, the preference for printed support in reading academic texts, the use of internet research to expand vocabulary, the request for help from teachers and the use of monitoring, offered by the university. The study concludes that some difficulties are not only related to the issue of fluency in the Portuguese language spoken in Brazil, but also to the unfamiliarity with reading and writing practices in the academic field. We also indicate the asymmetry between the northern countries in relation to Brazil when it comes to the internationalization of the university.

Keywords: Academic literacy. Foreign students. High education. University writing. Strategies.

Resumen: En este artículo analizamos las estrategias desarrolladas por los estudiantes extranjeros para hacer frente a las demandas del contexto académico en una universidad pública brasileña. Los datos analizados se derivan del trabajo de la Disertación de Santos (2019) y se recogieron en el segundo semestre de 2017 en la Universidad Federal de São João del Rei. La base teórico-metodológica se basa en los Nuevos Estudios de la Literacidad y en las aportaciones de la sociología de Pierre Bourdieu. Se realizaron 14 entrevistas semiestructuradas con estudiantes de nueve países diferentes, matriculados en cursos en todas las áreas excepto las humanidades. Se preguntó a los estudiantes sobre su llegada al Brasil, las actividades desarrolladas en la universidad y sus dificultades en las materias de los cursos a los que estaban inscritos. Las entrevistas fueron grabadas y transcritas para comprender los recursos movilizados por los estudiantes para sortear estas posibles dificultades. Los resultados muestran la gran variedad de estrategias de estudio, entre ellas la solicitud de ayuda de los colegas brasileños para satisfacer las exigencias de los cursos, la preferencia por el soporte impreso en la lectura de textos académicos, el uso de la investigación en Internet para ampliar el vocabulario, la 
solicitud de ayuda de los profesores y el uso de la vigilancia, ofrecida por la universidad. En el estudio se llega a la conclusión de que algunas dificultades no sólo están relacionadas con la cuestión del dominio del idioma portugués que se habla en el Brasil, sino también con el desconocimiento de las prácticas de lectura y escritura en el ámbito académico. También indicamos la asimetría entre los países del norte en relación con el Brasil, en lo que se refiere a la internacionalización de la universidad. Palabras-clave: Literacidad académica. Estudiantes extranjeros. Enseñanza superior. Escritura universitaria. Estrategias.

Recebido em 14 de junho de 2020 Aceito em 19 de dezembro de 2020

\section{INTRODUÇÃO}

0 campo de estudos dos Letramentos Acadêmicos no Brasil é relativamente recente. As primeiras publicações, em nosso país, surgem nesta última década, como se observa em Marinho (2010), Macedo e Barroso (2010), Macedo e Neves-Junior (2016), Macedo (2017) e Fiad (2011, 2015). Derivado dos Novos Estudos do Letramento (STREET, 1984; BARTON; HAMILTON; IVANIC, 2000), a perspectiva proposta por Lea e Street (1998) visa a contribuir para uma compreensão dos processos que demonstram diferentes usos sociais da escrita no contexto do ensino superior. Os estudos que enfocam a construção de letramentos acadêmicos advêm de dificuldades ressaltadas por professores frente às expectativas imputadas aos alunos ingressantes advindos de grupos sociais menos favorecidos socialmente na década de 1990, momento no qual houve uma significativa expansão universitária no reino Unido (LEA; STREET, 1998).

0 modelo dos Letramentos Acadêmicos (academic literacy), como estes autores denominam (LEA; STREET, 1998), busca apresentar uma alternativa aos, até então, modelos tradicionais e recorrentes, identificados no Ensino Superior do Reino Unido Modelo de Habilidades de Estudo e Modelo de Socialização (study skills e academic socialisation, respectivamente). As pesquisas que consideram esta perspectiva têm mostrado impasses entre as expectativas institucionais e as habilidades demonstradas por alunos ao lidarem com as demandas do ensino superior, ocasionando em solicitações e correções "misteriosas" aos alunos (LILLIS, 1999) e aumento em demasia do que seria um discurso que enaltece o défcit destes na realização, principalmente, de textos escritos de cunho avaliativo. 
0 principal foco dos estudos no Brasil tem sido o processo de produção da escrita acadêmica por estudantes brasileiros em diferentes áreas do conhecimento ${ }^{3}$. Nossa pesquisa, por outro lado, tem como foco estudantes estrangeiros, matriculados em uma universidade brasileira. A fundamentação teórico-metodológica inspira-se nos Novos Estudos do Letramento, considerando a perspectiva de Letramentos Acadêmicos como uma abordagem que deriva desses estudos, inspirada também nas contribuições da sociologia de Pierre Bourdieu. Tais contribuições nos auxiliam a delinear o campo acadêmico como um campo de poder no qual determinados capitais são privilegiados, em detrimento de outros, o que irá influenciar nos processos que tornam possivel as práticas sociais de letramento no e para o ambiente universitário.

Interessamo-nos pela compreensão das práticas sociais nas quais se engajam os estudantes estrangeiros no Brasil que, por meio de processos de mobilidade internacional desenvolvem atividades acadêmicas em nosso país. Para Morosini e Nascimento (2017, p. 02), "via de regra, [a internacionalização da educação superior] está relacionada à qualidade, à excelência, à inovação, ao conhecimento e a outros diferentes temas, destacando-se, na grande parte das vezes, a contribuição positiva dessa presença." Contudo, ainda se desenvolvendo timidamente, a internacionalização, que significa mais que a pura mobilidade física de estudantes e pesquisadores de um país para o outro, carece de significados estratégicos para os países envolvidos nestes processos, tendo como objetivo principal a promoção do desenvolvimento nacional em um nível mais elevado (MIRANDA; STALLIVIERI, 2017).

Neste interim, nossa pesquisa busca compreender os desafios enfrentados pelos estudantes ao lidarem com o campo acadêmico no Brasil e identificar estratégias desenvolvidas não apenas pelos estudantes estrangeiros, mas também por professores e em nível institucional mais amplo, para lidarem com os desafios decorrentes do estudo em um diferente país, com o ensino ofertado em idioma diferente daquele dominado por eles, em muitos casos. Os dados analisados encaminham proposições acerca das práticas de internacionalização no Brasil em dois níveis: individual e institucional. No que se refere ao primeiro, o texto busca apresentar experiências acerca do campo de ensino do português para estrangeiros para pesquisadores, produtores de material didático, professores, dentre outros leitores. Quanto ao segundo, referimo-nos à importância de se reconhecer o perfil dos estudantes estrangeiros pelos órgãos educacionais sobretudo no aperfeiçoamento da rede de recepção lexame nacional CELPE-Bras, editais de mobilidade, programas e bolsas de integração e outros). 
0 texto está organizado da seguinte maneira: inicialmente, tratamos das características evidenciadas nas pesquisas do campo dos Letramentos Acadêmicos, bem como da caracterização de Campo Científico e do conceito de estratégia, mais especificamente aqui como estratégias de estudos e; em seguida, apresentamos considerações sobre a metodologia de pesquisa; logo adiante, discutimos os resultados; finalmente, tecemos algumas considerações finais.

\section{PERCURSO METODOLÓGICO}

Os dados analisados neste estudo foram produzidos por meio de entrevistas individuais com 14 dos 28 estudantes estrangeiros, matriculados na Universidade Federal de São João del Rei (UFSJ) no ano de 2017, falantes de inglês, francês, espanhol e o português. ${ }^{4}$ No momento da pesquisa não havia alunos estrangeiros das áreas de ciências humanas matriculados na universidade, por essa razão, destacamos a predominância de estudantes vinculados à cursos relacionados às ciências exatas, biológicas e engenharias nesta pesquisa.

Em relação às entrevistas, mais especificamente, organizamos um roteiro com perguntas semiestruturadas, baseando-nos na pesquisa realizada por Macedo e Barroso (2010), objetivando investigar a relação do aluno com o ambiente acadêmico lescrita e outras práticas) em língua estrangeira (português brasileiro) no ambiente da universidade. As entrevistas duraram entre 30 e 40 minutos, nove ocorreram presencialmente e cinco

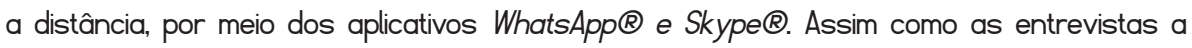
distância, as presenciais tiveram seus áudios gravados e as falas foram transcritas. Apesar da condição de estrangeiros, de diversas nacionalidades, não houve a necessidade de intérprete para que as interações entre entrevistadoras e entrevistados ocorressem, já que, cada um, seja por meio de experiências prévias ou posteriores à vinda ao Brasil, expressava certo domínio da língua portuguesa falada e escrita.

0 conjunto das entrevistas constituiu-se de um único arquivo, visitado e revisitado muitas vezes, até que pudéssemos estabelecer relações entre as falas dos alunos buscando mapear sentidos por eles atribuídos aos desafios que enfrentavam para se adaptar ao contexto acadêmico da universidade (BAKHTIN, 1929/1995). Além disso visamos a compreensão das vivências, tendências e tensões pelas quais os indivíduos entrevistados vivenciam (BOURDIEU, 2007) durante os processos que culminam na construção dos letramentos acadêmicos em nossos país. A partir dos sentidos identificados em cada entrevista, as

Estes últimos, advindos de países lusófonos como Cabo Verde, na África e Timor Leste, na Oceania. 
estratégias citadas por eles foram mapeadas em outro arquivo, com o intuito de produzirmos um dado quantitativo e, desta maneira, compreendermos quais estratégias foram mais recorrentes nos diálogos. Assim, as análises das entrevistas incluem tanto a quantificação das estratégias que se repetem quanto a análise dos sentidos produzidos por cada aluno ao descrever seu processo de inserção no ambiente acadêmico.

Os estudantes são oriundos de diversos países da África, da Ásia e da América Latina, matriculados em sete diferentes cursos. Em sua maioria, são de países em desenvolvimento ou subdesenvolvidos, como se observa no quadro abaixo. Cabe destacar que o tipo de mobilidade varia entre mobilidade de grau e mobilidade de crédito, bem como em relação aos diferentes tipos de acordos internacionais estabelecidos entre a universidade e os países destes estudantes. Na mobilidade de grau o estudante realiza toda a sua formação no Brasil e adquire um diploma da instituição brasileira. Em geral, os alunos estabelecem essa relação por meio do PEC-G, conhecido como o programa que mais atrai estudantes para o ensino superior brasileiro. A mobilidade de crédito consiste no chamado intercâmbio', no qual o estudante permanece por seis meses ou um ano na instituição e aproveita os créditos das disciplinas cursadas aqui em suas instituições de origem.

Quadro 1 - Participantes por pseudônimo, país de origem, idioma oficial, forma de vínculo e curso

\begin{tabular}{|l|l|l|l|l|}
\hline \multicolumn{1}{|c|}{ PSEUDÔNIMO } & \multicolumn{1}{|c|}{ PAÍS } & IDIOMA OFICIAL & \multicolumn{1}{c|}{ MOBILDADE } & \multicolumn{1}{c|}{ CURSO } \\
\hline Anderson & Timor Leste & Português & Grau & Engenharia de Produção \\
\hline Suzan & México & Espanhol & Crédito & Engenharia de Produção \\
\hline Mirian & França & Francês & Crédito & Engenharia Mecânica \\
\hline Lívia & Chile & Espanhol & Grau & Medicina \\
\hline Nádia & Peru & Espanhol & Grau & Medicina \\
\hline Laura & Alemanha & Alemão & Crédito & Psicologia \\
\hline Mário & Timor Leste & Português & Grau & Engenharia de Produção \\
\hline Letícia & México & Espanhol & Crédito & Engenharia de Produção \\
\hline Vivian & Timor Leste & Português & Grau & Ciências contábeis \\
\hline Márcia & São Tomé e Príncipe & Português & Grau & Bioquímica \\
\hline Jéssica & Cabo Verde & Português & Grau & Bioquímica \\
\hline Joaquim & Cabo Verde & Português & Grau & Engenharia Agrônoma \\
\hline Nilson & Honduras & Espanhol & Grau & Engenharia Agrônoma \\
\hline Marisa & São Tomé e Príncipe & Português & Grau & Engenharia Agrônoma \\
\hline
\end{tabular}

Fonte: os autores.

Para muitos dos estudantes africanos e latino-americanos, estudar no Brasil foi a única possibilidade de formação em nível superior na área por eles escolhida, como se pode 
inferir nas entrevistas analisadas na próxima sessão. Dentre os estudantes participantes, destacamos apenas duas estrangeiras oriundas de países europeus (Alemanha e França), com vínculos de curta duração, de seis meses a um ano. Os demais são vinculados ao PEC-G (Programa de Estudantes Convênio de Graduação) do MRE (Ministério das Relações Exteriores), ou convênios semelhantes a esse, em parceria com o Ministério da Educação e, para se matricularem, tiveram de apresentar um certificado de Proficiência em Língua Portuguesa, chamado CELPE-Bras. Esse documento não é exigido aos estudantes intercambistas. 0 quadro indica que os estudantes escolheram cursos cujo diploma é mais valorizado no mercado de bens simbólicos (BOURDIEU, 1989), se comparado com os cursos das áreas de humanidades. A seguir tecemos algumas considerações sobre o campo científico, os letramentos acadêmicos e as estratégias desenvolvidas pelos estudantes.

\section{CONSIDERAÇÕES SOBRE CAMPO CIENTÍFICO, LETRAMENTOS ACADÊMICOS E ESTRATÉGIAS}

Os campos sociais apresentam requisitos para a inserção e permanência dos sujeitos conforme analisa Bourdieu (1983, 1996). São exemplos de campos sociais o campo jornalístico, o campo jurídico, o campo econômico e, o que nos interessa aqui, o campo acadêmico/científico. Os campos, apesar de parecerem semelhantes, possuem autonomia entre si, com diferentes regras para a entrada e ascensão: “ 0 que faz com que as pessoas corram e concorram no campo científico não é a mesma coisa que faz com que elas corram e concorram no campo econômico." (BOURDIEU, 1996, p. 148). Cada campo é constituído por determinado capital simbólico. "O capital simbólico é um capital com base cognitiva, apoiado sobre o conhecimento e o reconhecimento." (BOURDIEU, 1996, p. 150).

Aquele que se insere no campo é jogador, se interessa pelo jogo e, por seu interesse se movimenta. Para o bom jogador, o sentido do jogo é incorporado e tal sentido é traduzido pelo habitus considerando o sentido histórico e futuro do jogo. Ele se adianta, se atrasa, mas joga, mesmo não tendo tão claras as regras que conduzem o jogo (BOURDIEU, 2008). 0 habitus seria uma disposição daqueles que, inseridos em um campo social, se movimentam, tomam suas decisões, jogam, ascendem socialmente sem, contudo, se orientarem de maneira racional para que tais movimentos ocorram. Quem se dispõe a jogar determinado "jogo", em determinado campo, lança mão de estratégias para o alcance de seus objetivos. A estratégia:

[...] é produto do senso prático como sentido do jogo, de um jogo social particular, historicamente definido, que se adquire desde a infância, participando das atividades sociais [...] isso supõe uma invenção permanente, 
indispensável para se adaptar às situações indefinidamente variadas, nunca perfeitamente idênticas. (BOURDIEU, 2004, p. 81).

Quanto mais incorporadas estiverem estas disposições aos participantes do campo ou do jogo, maior será a identificação destes com as regras e as estratégias a serem desenvolvidas, que estão presentes mesmo que não estejam estabelecidas em formato de código escrito. Para tanto, é necessário que se compreenda que diferentes habitus estão presentes na relação entre os estudantes estrangeiros e a universidade, relação que perpassa pelas estratégias utilizadas, em face da compreensão do "sentido do jogo".

Diversas são as regras estabelecidas pelos documentos que regem os convênios internacionais, os regimentos da universidade, as leis brasileiras que deverão ser observadas pelos estudantes para continuarem no Brasil, as ementas das disciplinas cursadas como norteadores das trajetórias de estudo, as informações sobre a concessão de eventuais custeios de permanência no Brasil, dentre outros. Mas a observação das regras não codificadas se faz presente e em muito importa para a definição das expectativas sobre o desempenho, não apenas para os estudantes estrangeiros, mas para todos os estudantes vinculados ao ensino superior.

Além dos conceitos de campo, habitus e estratégias, o conceito de capital cultural se torna fundamental para compreendermos as estratégias já que "o sucesso escolar dependeria, em grande medida, do capital cultural possuído pelos indivíduos." (NOGUEIRA; NOGUEIRA, 2004, p. 42). 0 capital cultural está presente nos sujeitos de três formas: incorporado, objetivado e institucionalizado. 0 capital cultural em seu estado institucionalizado diz respeito à confirmação que advém de uma certificação ou diploma acerca daquele capital cultural adquirido por meio dos investimentos em educação. Assim, o capital cultural é resultante das trajetórias pessoais marcadas também por uma espécie de "herança" deixada por seus antecessores (BOURDIEU, 2008).

As práticas de letramento constituídas no interior do campo científico podem evidenciar marcas do capital cultural dos sujeitos bem como as estratégias por eles criadas para alcançarem seus objetivos neste campo. Lea e Street (1998) apontam três modelos que têm subsidiado as práticas de letramentos acadêmicos ${ }^{5}$ das instituições de ensino superior. 0 modelo de competências de estudo leva em consideração as habilidades necessárias com a linguagem acadêmica, entendendo leitura e escrita como ações autônomas e, uma vez apreendidas são facilmente transferíveis a diferentes contextos. 0 modelo de socialização

5 Aqui entendemos letramentos acadêmicos como a construção das habilidades necessárias para o uso da leitura e da escrita no contexto universitário (LILLIS; SCOTT, 2007). Assim, o termo pode ser entendido no plural ou no singular. Contudo, quando tratamos da Perspectiva dos Letramentos Acadêmicos, esse termo virá necessariamente no plural e em letra maiúscula, já que indica um campo teórico. 
acadêmica preza a interação entre os sujeitos como uma forma de aquisição de conhecimentos, no qual o professor seria um agente com função de mediação na apropriação da cultura acadêmica. Como uma alternativa aos modelos identificados, os autores defendem o exercício de um terceiro modelo, o dos Letramentos Acadêmicos. Tais modelos não são excludentes, porém este último reconhece a leitura e a escrita como práticas sociais e culturalmente situadas, constituídas por relações de poder.

Trabalhos como os de Lillis (1999, 2001) e Lillis e Scott (2007) evidenciam, inclusive, que as regras que regem as produções acadêmicas são práticas misteriosas aos estudantes, obtendo sucesso àqueles que conseguem perceber os elementos de poder implícitos e constitutivos do campo acadêmico. Nesse sentido, as práticas promovidas no contexto acadêmico são multifacetadas, plurais, incluem desde as especificidades da linguagem acadêmica, a diversidade de gêneros textuais a serem lidos e produzidos em meio a relações e interações entre alunos e docentes, permeadas por relações de poder e ideologia, não sendo, portanto, neutras. Ocorrem no interior de uma cadeia de interação verbal (BAKHTIN, 1929/1995) da qual os estudantes fazem parte, mediadas pela escrita, e incluem desde a interação com os próprios colegas estrangeiros, com os estudantes brasileiros, com seus professores, dentre outros, não se restringindo ao espaço da sala de aula. Na próxima seção, apresentamos as considerações dos alunos entrevistados sobre sua relação com o português no ambiente acadêmico.

\section{O QUE DIZEM OS ESTUDANTES SOBRE OS USOS DA LÍNGUA PORTUGUESA NO CONTEXTO ACADÊMICO}

Todos os estudantes relataram ser desafiante falar e escrever na língua portuguesa do Brasil, inclusive os advindos de países lusófonos. Cientes disso, eles buscam desenvolver estratégias para permanecerem e obterem êxito no campo acadêmico e alcançarem a titulação no tempo previsto. Como nos lembra Bourdieu (2004), tais estratégias podem ser inconscientes. Porém, o fato é que elas estão presentes e contribuem, em grande medida, para que esses estudantes continuem jogadores deste jogo que é o campo científico.

Observamos que a relação estabelecida com a língua portuguesa é diferenciada para cada estudante, considerando sua origem. Para Márcia, de São Tomé e Príncipe, a língua portuguesa se apresentou como uma dificuldade pontual no início do curso. Apesar de ser a língua oficial em seu país, Márcia afirma que os diferentes sotaques no Brasil e as gírias dificultam a comunicação com os brasileiros. Porém, os obstáculos na compreensão são 
superados em decorrência da convivência, da cooperação dos professores e do interesse dos estrangeiros na aprendizagem da língua falada no Brasil. Segundo a estudante,

\begin{abstract}
E quanto à língua, no início foi um pouquinho dificil, até tem um professor que ele sempre fala assim: "se eu estiver falando rápido gente me fala que nos anos anteriores aqui eu tinha uma aluna que ela não entendia nada que eu falava". Era eu, no caso. "Então, peçam pra falar devagar". Mas, depois já está melhor, é só mesmo por causa do sotaque. Gírias eu não entendo, algumas eu não entendo mesmo, mas, de resto, eu já estou melhor agora. (Márcia, São Tomé e Príncipe) (informação verball.
\end{abstract}

Esse fato também é anunciado por Joaquim, aluno de Cabo Verde, na época da pesquisa, o aluno estava em fase de conclusão do curso. Joaquim aponta também o desafio de compreender as variações linguísticas do Brasil (BAGNO, 2007; FARACO, 2015), a adaptação ao ensino da universidade também se mostrou desafiadora. Segundo o estudante, foi necessário algum tempo para perceber que realmente estava cursando o ensino superior em outro país, com uma cultura acadêmica própria distinta da cultura acadêmica da escola básica cursada em seu país. Logo, foi necessário aprender a viver no Brasil tal como os brasileiros o fazem, considerando as práticas típicas do ensino superior, encontrando nos colegas e professores agentes que apontaram as diferenças de significados em palavras que lhe causavam estranhamento:

\footnotetext{
0 português do Brasil é um pouco diferente do português que a gente costuma falar, lá lem Cabo Verdel a gente fala o português de Portugal e algumas pronúncias, algumas coisas, nas matérias, por exemplo, inicialmente, precisa falar algumas coisas que eu não entendia o que a pessoa estava falando [...] (Joaquim, Cabo Verde) (informação verbal).
}

Este fator se intensifica com a inserção destes estudantes nos diferentes Estados brasileiros. Todos os estudantes estavam localizados em unidades da universidade presentes em Minas Gerais e, conforme destacam os autores Peres (2006), Dias (2011) e Ribeiro, Soares e Lacerda (2012), o dialeto mineiro apresenta processos de variação e mudança no processo comunicativo. Esses autores adotam alguns exemplos para essas variações como o uso dos verbos existenciais (ter, haver e existir), o próprio sentido da expressão 'mineiridade' desenvolvida por Gilberto Freyre e os usos e modificações das formas você, ocê e cê na cidade de Belo Horizonte MG. Tais fatores, especificamente em Minas proporcionam diferentes nuances nas trocas comunicacionais, principalmente para os estudantes em mobilidade de crédito, cuja estadia em nosso país é menor e não há a exigência de proficiência na língua portuguesa. 
Joaquim destaca que cada país na África apresenta uma alternativa para lidar com a língua portuguesa. Em São Tomé e Príncipe, o português é considerado a língua materna e a língua oficial, enquanto que em Cabo Verde esse idioma figura apenas como língua oficial, sendo o crioulo a lingua materna (considerada oficialmente como um dialeto). Sendo assim, o português acaba sendo uma exigência curricular nas escolas, mas não é falado no cotidiano dos cabo-verdianos. Então, para aqueles que não falam a língua portuguesa no seu dia a dia, é mais complicado compreender a diversidade linguística do Brasil, mesmo conhecendo as novelas brasileiras e outras influências que chegam do Brasil. A observação de Joaquim evidencia que ele tem consciência das relações entre língua e poder (BOURDIEU, 1983; STREET, 1984), da sua não neutralidade na medida em que ela pode ser usada para reproduzir as desigualdades sociais e para distinguir sujeitos de acordo com a classe social:

0 pessoal associa a lingua com a classe social a pessoa considera que quem fala português são pessoas nobres da alta sociedade, [...] eu acho que colocar a língua como fator de desigualdade social, acho uma coisa ridícula, acho que a pessoa fala crioulo, a pessoa fala o que ela quiser. (Joaquim, Cabo Verde) (informação verbal).

0 mesmo parece ocorrer no Timor Leste que tem como idiomas oficiais o tétum e a lingua portuguesa, mas segundo Mário, residente há dois anos e meio no Brasil, aqueles que se comunicam no país em português ou em inglês com pessoas que não são estrangeiras, são considerados arrogantes:

Lá no Timor Leste eu tinha conhecimento do inglês e o português por estudar na faculdade, mas não tenho conhecimento de falar, comunicar entre as pessoas não, porque é difícil pra comunicar porque assim, o nosso idioma também tem, o nosso idioma aqui chama tétum e o nosso idioma influencia a nós que não comunica bem de português porque se comunicar bem, eu falei em português as pessoas falam: "ele é muito arrogante" assim em nosso país [...] falar português e inglês com as pessoas que não são estrangeiros não é bom. (Mário, Timor Leste) (informação verbal).

Anderson, outro aluno timorense que já vive há dois anos no Brasil, apontou um grupo religioso da universidade como um importante espaço para o desenvolvimento da sua proficiência na língua portuguesa. Segundo o aluno, apesar de ter sido aprovado no exame CELPE-Bras, nos primeiros dias de estudo não falava com ninguém, simplesmente porque não sabia se comunicar de uma forma que as pessoas pudessem compreendê-lo. Outra dificuldade por ele citada relaciona-se à compreensão escrita nomeada como uma dificuldade de interpretar os textos do curso. 
0 estudante percebe a diferença da especificidade da linguagem acadêmica, diferente daquela usada no dia a dia e atribui suas dificuldades a essas diferenças. Ao citar uma atividade avaliativa, em que o professor orientou que fosse realizada a leitura de um texto e posterior apresentação para a turma, Anderson afirmou ter solicitado a um colega que lesse e explicasse a ele sua interpretação do texto, para que ele pudesse apresentá-lo - o que demonstra uma das estratégias utilizadas para se apropriar das especificidades da leitura e da escrita na universidade, ou seja, dos letramentos acadêmicos enquanto práticas sociais (LEA; STREET, 1998).

De acordo com Anderson, o português é utilizado como língua oficial de Timor Leste apenas porque foi muito útil para a libertação dos timorenses da dominação asiática, já que os asiáticos não compreendiam o português.

\footnotetext{
Os que sabem bem o português foi os nossos avôs e bisavôs porque eles viveram na época da colonização do português e nós não sabemos bem porque quando os portugueses saíram do nosso pais, foi outro pais que nos invadem, a Indonésia. Então a gente entende melhor a língua da Indonésia do que o português [...]. Mas a gente usa o português como nossa língua oficial porque na nossa luta a gente só conversa com 0 português porque o Indonésia não sabe português. Por isso nós usamos o português como língua oficial porque nos ajudou muito durante o processo da nossa luta para tomarmos a nossa independência. (Anderson, Timor Leste) (informação verbal).
}

Vê-se aqui a consciência sobre os usos da língua do colonizador em favor do processo de descolonização e independência do país (MIGNOLO; CARBALLO, 2014). Fica evidente nas falas de Mário, Joaquim e Anderson que o domínio da língua portuguesa, em seus países, é fator de distinção social (BOURDIEU, 1983) e indica uma diferença de classe, causando estranhamento se usada fora do ambiente escolar. Assim, para os alunos advindos de países lusófonos, a relação com a língua portuguesa é distinta, dá-se pela necessidade de dominar a língua oficial considerada socialmente legítima e indicação de status social, o que causa, para eles, algum constrangimento junto às pessoas mais próximas.

Observamos alguns desafios semelhantes para os estudantes falantes de espanhol. Nilson, de Honduras, vivendo há dois anos no Brasil, aponta que os maiores desafios foram a distância da família e a questão da língua. Para ampliar a fluência na língua portuguesa, Nilson morou no Brasil um ano antes de ingressar no ensino superior. Fez um curso no Rio de Janeiro que o preparou para realizar o exame de proficiência em língua portuguesa para estrangeiros, o CELPE-Bras. Entretanto, no contexto da universidade, o aluno relata que, com o tempo, suas dificuldades foram diminuindo. 
Nilson afirma que, em algumas circunstâncias, a língua portuguesa acaba gerando situações complicadas, ocasionando problemas no momento da realização de avaliações formais. Segundo o aluno, um professor, ao aplicar uma prova, disse que não seriam permitidas perguntas sobre as questões da avaliação, porém, Nilson gostaria de saber se sua interpretação acerca do que estava sendo solicitado estava correta, ou seja, ele queria compreender melhor o enunciado de uma das questões da avaliação. Então, ele acabou respondendo o que havia compreendido, porém, quando recebeu sua prova corrigida, o professor afirmou que as respostas às questões que the haviam gerado dúvidas estavam incorretas. Nilson acabou contornando a situação ao explicar oralmente ao professor o que não havia conseguido expressar ao responder sua prova e o professor acabou considerando:

\footnotetext{
Nesse caso eu consegui sair bem, eu expliquei para ele, mas acho que no geral prejudica um pouco sim. Às vezes você tá querendo explicar com sua ideia o que você sabe, às vezes você não sabe o jeito certo de explicar em português, aí você explica e o professor não entende ou talvez falta algum conectivo, falta alguma coisa para entender o melhor jeito então acho que prejudica um pouco. (Nilson, Honduras) (informação verbal).
}

A situação enfrentada por Nilson pode ter ocorrido por desconhecimento da situação formal de realização de uma prova escrita no contexto de universidade brasileira, gênero típico do letramento escolar e acadêmico, utilizado para que o professor avalie o desempenho de seus alunos. Por isso mesmo, foi alertado que não seriam permitidas perguntas sobre as questões da prova, uma das regras básicas desse tipo de prática social de uso da escrita. Assim, suas questões com a língua provavelmente referiam-se ao domínio de gêneros específicos do campo acadêmico, das normas e regras que constituem a situação formal de avaliação, mas pode também referir-se a escrita das respostas da prova o que possibilitou o uso da explicação oral ao professor. 0 professor cooperou com o estudante ao aceitar suas explicações orais, demonstrando que a interação menos assimétrica entre professor e estudantes pode ser um fator decisivo na superação dos desafios dos estudantes estrangeiros no ambiente acadêmico não apenas em relação à língua, mas a outros aspectos próprios da cultura acadêmica que a diferencia dos demais espaços sociais.

Suzan, do México, passou apenas seis meses no Brasil. Ela destacou que quando chegou, foi alertada por colegas estrangeiros sobre palavras comumente faladas em espanhol e que geram uma conotação negativa ao serem proferidas no Brasil. Para ela, a forma como os professores falam também aparece como um complicador no entendimento das aulas, referindo-se aos diferentes sotaques existentes. Apesar disso, a aluna, que inicialmente se esforçava para compreender melhor a língua portuguesa do Brasil, hoje entende o que é dito e não se esforça para falar em português, já que considera ser bem compreendida ao falar 
espanhol". "Me dei conta que é muito similar e deixei de me preocupar porque as pessoas me entendem quando eu falo. Só que cortam as palavras." (Suzan, México, tradução nossa) (informação verbal).

A intercambista Letícia, também do México, afirma não ter realizado provas para vir para o Brasil. Segundo ela, não sabia falar português antes de vir para cá e, quando chegou, não entendia o que era dito pelas pessoas. Porém, em pouco tempo começou a compreender melhor o idioma e, diferentemente de Suzan, se esforça para falar em português. Reiterando o que foi dito por outros estrangeiros, dentre os maiores desafios da interação em língua portuguesa estão a pronúncia das palavras e a compreensão dos diferentes sotaques.

\footnotetext{
[...] eu acho que depois de três semanas comecei já entender melhor o que vocês falavam porque primeiro nada compreendia, compreendia nada. Agora não sei, agora que já entendo, não acho essa dificuldade, mas quando eu cheguei, não sei, é muito dificil, seu sotaque é muito difíicl. E a pronunciação de algumas letras de você é muito diferente de espanhol. Não, acho que eu não sabia o que [...] como era essa pronunciação. (Letícia, México) (informação verbal).
}

As questões relativas à comunicação e à interação na universidade se apresentam de modo diferente para a pesquisadora francesa e a estudante alemã. Mirian, pesquisadora no laboratório de um curso de pós-graduação pelo período de seis meses, afirma que esperava encontrar pessoas que falassem línguas dominadas por ela, como o espanhol, o francês e o inglês. Sua proficiência em português não the permitia uma compreensão satisfatória do que as pessoas falavam. "Porque aqui não há muitas pessoas que falam inglês e espanhol então eu não falava bem português, então foi muito difícil." (informação verbal). Importante ressaltar que, conforme explicado por ela, em sua universidade, na França, os alunos devem realizar dois estágios, um na própria França e outro no exterior. Ela diz que as pessoas costumam escolher países próximos à França, que adotam o francês, como a Suíça ou a Bélgica. Porém, ao realizar um estágio no Brasil, Mirian resolveu subverter as escolhas comumente realizadas por seus colegas.

Por outro lado, ela está inserida em um laboratório que integra outros estrangeiros; então, em determinados momentos ela se depara com a necessidade de se comunicar em diferentes línguas, como o francês, o português e o inglês, sendo que essa multiplicidade acaba por confundi-la. “[...] sim porque no laboratório há outra menina que fala francês, então

$6 \quad$ Na entrevista Suzan respondeu às questões em língua espanhola, as respostas aqui apresentadas foram traduzidas para a língua portuguesa.

$7 \quad$ "Me di cuenta de que es muy similar y dejé de preocuparme porque la gente me entiende cuando hablo. Solo ellos cortan las palabras." 
devo falar francês e inglês e português e na minha cabeça é muito difícil." (Mirian, França) (informação verbal). Por outro lado, o fato de falar três línguas the possibilita uma interação mais efetiva no contexto da pesquisa, não causando prejuízo no trabalho a ser desenvolvido.

Assim como Mirian, destacamos o caso da intercambista alemã, Laura, que aqui chegou sem falar a língua portuguesa e, mesmo tendo fluência em alemão e inglês, não encontrou professores e colegas que pudessem com ela interagir. Segundo a aluna, após demonstrar dificuldades no acompanhamento das aulas, uma monitora falante de inglês the foi designada pela instituição e, assim, as atividades das disciplinas puderam ser realizadas mais tranquilamente. Laura afirma que se sentiu isolada em decorrência da questão linguística e, por estar em um lugar em que quase ninguém fala inglês, as pessoas geralmente não a compreendiam:

Uma lingua muito dificil, muito diferente, uma língua que eu não falo nada, mais ou menos nada, não falo muito e foi muito difíil l...] nenhuma pessoa em São João fala inglês, não muitas [...] foi muito difícil porque não entendia nada. Eles não falam inglês e foi muito dificil. (Laura, Alemanha) (informação verbal).

Apesar das limitações na compreensão e na fluência em língua portuguesa, Laura escolheu se expressar em português, demonstrando que os poucos meses que passou na universidade contribuíram para a sua aprendizagem. Constatamos que as expectativas de Miriam e Laura eram semelhantes na escolha do Brasil. Não falantes de língua portuguesa, esperavam aqui encontrar professores e outros estudantes que falassem outros idiomas além do português. Conforme expusemos, não se exige proficiência em língua portuguesa para estudantes ou pesquisadores que vêm ao Brasil passar um curto período.

Em sentido contrário, estudantes brasileiros que desejam fazer intercâmbios no exterior, especialmente os países do Norte $\mathrm{Global}^{8}$ devem apresentar proficiência em inglês ou na língua do país de destino, uma exigência desses países, cumprida pela nossa política de internacionalização. Esse fato demonstra, de forma clara, a relação assimétrica entre o Brasil e os países do Norte (AZEVEDO; SLLVA-JUNIOR; CATANI, 2015) ao adotarmos uma política de mobilidade estudantil e docente sem contrapartida. Brasileiros que estudam fora não contam com suporte como o oferecido pela UFSJ à aluna alemã - um tradutor/monitor durante as aulas. 0 pressuposto é o de que devem dominar a língua do país de destino, tendo que apresentar um teste de proficiência, como se observa nos editais de mobilidade estudantil e de financiamento de pesquisadores brasileiros no exterior, promovidos pelas agências de fomento.

\footnotetext{
Refere-se aos países centrais do sistema capitalista considerados desenvolvidos em relação ao Sul-Global, países da periferia capitalista em todos os continentes.
} 
As falas dos estudantes e da pesquisadora francesa chamam a atenção para a questão linguística, central nos processos de internacionalização em casa (GONÇALVES, 2009). Os dados deixam claras as limitações enfrentadas por todos os alunos em relação à proficiência da língua portuguesa, indicando que o exame CELPE-Bras não é suficiente para garantir a fluência e a interação linguística desejada de imediato, devendo a universidade recorrer a outros recursos que promovam maior integração dos estrangeiros ao contexto acadêmico. A variação linguística da língua portuguesa (BAGNO, 2007; FARACO, 2015), de acordo com todos os relatos, foi um dos elementos que desafiou a interação entre os estrangeiros e brasileiros nas aulas e fora da universidade. Esse conhecimento mais aprofundado da língua só se adquire num contexto de uso real, portanto, após a imersão no contexto brasileiro e em práticas de letramentos acadêmicos, como de fato ocorreu para a maior parte dos estudantes.

Na próxima seção, apresentamos o conjunto das estratégias dos estudantes para lidarem com as demandas do campo científico permeadas pela necessidade real de uso da leitura e da escrita na universidade.

\section{ESTRATÉGIIAS PARA APROPRIAÇÃO DE LETRAMENTOS ACADÊMICOS}

Apresentamos as estratégias relatadas tendo em vista a apropriação do "sentido do jogo" no campo científico para uma participação mais efetiva nesse espaço social. Tais estratégias são múltiplas e, não raro, indicadas por mais de um estudante. Muitas parecem ter se desenvolvido a partir da interação com brasileiros. Outras são trazidas por esses estudantes, advindas de suas experiências anteriores na escola e na família. Por fim, há estratégias desenvolvidas em comum acordo com os professores, que denotam o esforço dos docentes na inserção do estudante estrangeiro, com o reconhecimento de suas necessidades apresentadas no dia a dia das aulas.

\subsection{PEDIDO DE AUXÍLIO AOS COLEGAS BRASILEIROS}

A maior parte das estratégias refere-se ao pedido de auxilio aos colegas brasileiros (१2 estudantes, 86\%) e à realização de anotações das aulas em língua portuguesa e dos resumos de textos (11 estudantes, 79\%). A estudante alemã, Laura, recorreu a uma amiga brasileira bilíngue no auxílio com a escrita de textos. A colega escrevia os textos em 
português por ela ditados em inglês. Apesar do auxílio, Laura ainda não se percebia capaz de realizar todas as atividades acadêmicas que lhes foram designadas:

\begin{abstract}
Eu tenho monitora nas aulas, desde setembro, eles me deram. Mas, eu tenho um professor e ela, nós tínhamos que escrever um texto no final do semestre e eu acho que ele disse que eu posso escrever no inglês porque ele pode ler em inglês, ele não fala, mas ele pode ler e a outra faz uma avaliação mais fácil para mim, ele faz uma autoavaliação e a outra tem eletiva, não é prova, é uma tarefa para fazer na casa e eu tive uma amiga que ajuda. Ela ajuda que a nós falamos sobre as tarefas e falo o que eu acho e ele escreve os textos porque não posso escrever muito bom com a gramática e as palavras. (Laura, Alemanha) (informação verbal).
\end{abstract}

É perceptível na fala de Vivian, aluna do Timor Leste, a presença de seus colegas e amigos brasileiros no seu desempenho no curso em que trocavam resumos das aulas, compartilhavam conhecimentos de forma intensa. A ajuda prestada por eles parece diferente do evidenciado pelo estudo de Macedo e Barroso (2010), no qual era necessário que os estrangeiros demonstrassem previamente possuir determinados conhecimentos para que os brasileiros concordassem em estudar com eles.

Letícia aponta outra estratégia que privilegia a interação com os brasileiros. Ao conhecer um rapaz estudante do curso de Letras-Espanhol, eles combinaram de trocar seus conhecimentos em Português e Espanhol na qual todos os dias ambos se reuniam. Em um dia Letícia o ensinaria espanhol e durante todo o tempo eles falariam nesse idioma. No outro, seu amigo a ensinaria português. Tal estratégia se aproxima de uma ação de internacionalização em casa (GONÇALVES, 2009), realizada de forma espontânea, sem a mediação institucional, capaz de proporcionar ganhos para brasileiros e estrangeiros na aquisição de um novo idioma, como se constata na fala de Letícia:

\footnotetext{
Porque eu tenho outros amigos assim que fiz fora de aula que elas conversam comigo um estuda letras e ele falou que eu tenho que aprender espanhol, me ajuda que eu te ajudo com o português e você me ajuda e tá, um dia falamos todo dia em português, um dia falamos todo dia em espanhol e fazemos isso e agora ele já pode conversar em espanhol muito bem. (Leticia, México) (informação verbal).
}

Esses dados indicam que parece haver uma interação significativa entre brasileiros e estrangeiros e que os alunos estrangeiros constroem essa relação de forma estratégica, uma vez que percebem a abertura e a disposição dos colegas para cooperarem com a sua apropriação dos letramentos acadêmicos demandados no ensino superior ao mesmo tempo que também buscam fluência na Língua Portuguesa falada no Brasil. 


\subsection{ANOTAÇÕES EM CADERNO E OUTRAS MARCAS NA LEITURA DE TEXTOS ACADÊMICOS}

Na leitura de materiais impressos propostos pelos professores, Nádia, estudante peruana de medicina, afirma realizar um estudo sistemático, com uma leitura preliminar, em seguida, uma segunda leitura para grifar o que for importante - destacando em várias cores - e, por fim, aluna escreve um resumo, em forma de anotação, sobre o que foi lido, estratégia semelhante à apurada por Macedo (2017) quando investigou práticas de letramentos acadêmicos de estudantes brasileiros de um curso de mestrado em educação.

Mário, assim como outros colegas, utiliza-se da estratégia de anotar os termos e as palavras desconhecidas num caderno, juntamente aos seus significados correspondentes. Ele busca os significados perguntando ao monitor da disciplina, ao professor ou aos colegas brasileiros, demonstrando a importância de se ater ao contexto no qual a palavra está inserida, ou seja, determinado texto acadêmico. 0 caderno é lido algumas vezes ao dia, como uma forma de treinar as novas palavras. 0 aluno Nilson, da mesma forma, também faz anotaç̃̃es no caderno: "faço anotaç̃̃es no caderno, meu caderno está cheio, marcar no livro não, é mais anotações no caderno mesmo." (Nilson, Timor Leste) (informação verbal).

A estudante Suzan afirma ter adotado algumas estratégias de estudo, como desenvolver perguntas para os textos lidos, estratégia estimulada pelo pai e que passou a adotar em seus estudos no Brasil: "Quando estudo um texto, faço perguntas. Às vezes trato de sublinhar, mas não porque eram livros que tinham que devolver. Depois meu pai me disse para fazer perguntas e assim é mais fácil. Também faço anotações em espanhol sobre o texto." (Suzan, México) (informação verball). ${ }^{9}$

Além disso, Suzan sublinha os textos e faz anotações em um caderno único para todas as anotaç̃̃es das disciplinas, realizadas em sua lingua materna, o espanhol. Tal relato demonstra que a estudante chega ao contexto brasileiro com determinado habitus, adequado ao campo acadêmico, proveniente de suas origens, uma vez que foi orientada pelo pai a estudar por meio da elaboração de perguntas sobre os textos lidos.

Lívia, aluna do curso de medicina, assim como outros estudantes, utiliza a técnica de sublinhar os textos em seus momentos de estudo como estratégia de aprendizagem e nota que, geralmente, quando vai responder a questões abertas, se mostra muito repetitiva

$9 \quad$ "Cuando estudio un texto, hago preguntas. A veces trato de subrayarlo, pero no porque fueran libros que tuvieran que devolver. Entonces mi padre me dijo que hiciera preguntas y eso es más fácil. También tomo notas en español sobre el texto." 
na escrita, até que a ideia the pareça clara. Além disso, a leitura e a escrita repetidas são, para ela, formas de "reter a informação":

\begin{abstract}
Eu anoto umas 3 ou 4 vezes a mesma matéria para conseguir reter a informação. Eu faço assim, eu leio geralmente umas 2 ou 3 vezes o texto, eu primeiro sublinho a matéria, ai o mais importante aí depois eu releio o que eu sublinhei aí, se não ficar muito claro com o que eu sublinhei aí eu leio de novo aí eu escrevo o que é o mais importante. (Livia, Chile) (informação verbal).
\end{abstract}

Portanto, as estratégias desses alunos parecem indicar um diálogo intenso com os textos lidos em que sublinhar palavras, destacar trechos lidos, realizar anotações num caderno, criar glossário para ampliar o vocabulário, elaborar perguntas aos textos, fazem parte das práticas de leitura de textos acadêmicos.

\title{
5.3 APOIO DAS TECNOLOGIAS DIGITAIS E DA TU
}

Diferentemente de Suzan e Mário, Nádia prefere fazer fotos dos conteúdos escritos no quadro ou dos slides apresentados pelos professores. Segundo a aluna, ela e seus colegas de turma quase não escrevem, preferem fotografar o quadro e anotar apenas o que julgam ser estritamente importante para a aprendizagem. Outra estratégia que nos chama a atenção é utilizada por Nádia, Joaquim e outros estudantes: gravar as aulas. Porém, Joaquim afirma que nem todas elas são ouvidas. Algumas valem à pena serem gravadas, outras não, conforme destacamos no exceto abaixo:

\footnotetext{
Eu gravo a aula, aí quando eu chego em casa eu dou uma lida e estudo. Eu gravo, tem aulas que eu gravo, algumas eu ouço, outras não. Mas eu faço $\circ$ máximo para escutar. Mas tem matérias também que eu não gravo porque tem matérias que não adianta só quem estuda mesmo. (Joaquim, Cabo Verde) (informação verbal).
}

Nádia afirma que os professores que "falam muito depressa" não serão facilmente compreendidos se forem gravados. Neste caso, o mais indicado, segundo ela, é ficar atenta às explicações e anotar o que parecer ser mais essencial. 0 suporte digital também é bastante utilizado para melhorar a proficiência na fala, na escrita e na leitura por meio de pesquisas na internet, ao buscar o significado de termos desconhecidos, conforme Joaquim e Mário. 
Eu adoro pesquisar na internet, eu procuro melhorar meu português, a internet ela te dá outra visão, outras possibilidades que você pode tentar pra sua escrita e eu adoro escrever e isso ajuda, por um lado ajuda, aprender várias formas também de explicar o que você acabou de falar. (Joaquim, Cabo Verde) (informação verbal).

Outra estratégia dita pelos estudantes foi assistir às telenovelas brasileiras para uma ampliação do vocabulário. Vivian explica que, inicialmente, não assistia às novelas em seu país, porém, ao chegar no Brasil, percebeu que seria uma forma para melhor compreender algumas palavras faladas aqui, como afirma em seu relato: "aqui eu estou assistindo porque tem algumas palavras para ajudar e lá não, não assistia não." (Vivian, Timor Leste) (informação verbal).

\subsection{A RELAÇÃO COM O IMPRESSO E A ESCRITA ACADÊMICA}

Uma das perguntas da entrevista versou sobre o tipo de suporte utilizado pelos alunos para estudar, buscando identificar se havia uma preferência pelo impresso ou pelo digital. Surpreendentemente, a maioria dos entrevistados afirmou preferir materiais impressos com o argumento da facilidade de manuseio e da realização de anotações nos próprios textos. 0 dado nos surpreende justamente porque a maioria desses estudantes nasceram no contexto de expansão da internet e do mundo digital (PRENSKY, 2001). No caso de Márcia, por exemplo, a preferência pelo estudo a partir de materiais impressos se explica pela possibilidade de marcar informações importantes, entretanto, os materiais digitais também permitem fazer marcas nos textos. Além das marcações, a aluna ainda aponta a escrita de resumos:

\footnotetext{
Então, se for impresso tipo folheto, artigo, eu marco, marco a parte que eu achei interessante, importante, pra depois não ter que ler tudo de novo, pra não perder também, mais no livro, como não se pode marcar porque o livro não é meu, então eu tenho que pensar um negócio que eu achei interessante, basicamente vai dar um resumo, com o livro eu vou fazer o resumo. (Márcia, São Tomé e Príncipe) (informação verbal).
}

Márcia indica que a cada livro lido um resumo é escrito para a sistematização do conteúdo das aulas, evidenciando uma articulação entre leitura e escrita acadêmica no processo de apropriação do conhecimento. Joaquim assume gostar de escrever determinados gêneros que são comumente usados no ensino superior, como os artigos científicos, e esta é mais uma estratégia usada pelo aluno. Dentre os entrevistados foi o único que mencionou recorrer, de forma sistemática, à escrita de outros gêneros acadêmicos além do resumo: 
"Eu prefiro escrever coisas para a faculdade, eu adoro escrever artigo científico, trabalhos, esses negócios." (Joaquim, Cabo Verde) (informação verbal).

Jéssica afirmou gostar de ler livros relacionados às disciplinas como uma forma de avançar nos estudos e na fluência da linguagem acadêmica. Por meio da leitura dos livros, ela escreve resumos e pesquisa na internet as palavras desconhecidas. "Na verdade, agora eu estou lendo livros, eu estou lendo livros e estou fazendo resumo a partir do livro. Eu faço para estudar mesmo, entender melhor, para conseguir colocar na cabeça." (Jéssica, Cabo Verde) (informação verbal).

\subsection{A AUALIAÇÃO E A RELAÇÃO COM OS DOCENTES}

Para Lívia, estudante chilena de Medicina, não existe um entendimento dos professores acerca de sua condição de aluna estrangeira, sendo exigido o mesmo desempenho com a língua escrita dos alunos brasileiros, inclusive, com diminuição na pontuação em provas e trabalhos devido a erros ortográficos:

\footnotetext{
Para algumas provas, tem professor que até hoje eles me tiram ponto por causa da ortografia e pra mim, por que você vai tirar por causa da ortografia? Eu acho que, eu não questiono porque se ele fez sabendo que ele tá tirando ponto de uma pessoa que é estrangeiro pra que vai questionar? Aí eu fico na minha, eu tento melhorar o português, tento escrever mais. (Livia, Chile) (informação verball.
}

Nesse caso, a aluna, estrategicamente, prefere não questionar as atitudes dos docentes para não causar problemas em seu processo de aprendizagem provavelmente porque percebe que o questionamento da prática docente pelos alunos não é corriqueiro na cultura acadêmica. A partir do relato de Lívia, cabe-nos questionar: como os professores participam nesse processo de ensinar a estrangeiros, falantes de outras variações da língua portuguesa e de idiomas que eles não dominam? Lembramos que apenas seis dos 14 estudantes entrevistados citaram o auxilio de professores das disciplinas como estratégias para a apropriação de letramentos acadêmicos na instituição, contra 12 que solicitam ajuda dos colegas brasileiros. Contudo, segundo o relato dos estrangeiros, observa-se, geralmente, uma postura docente que visa à contribuição para minimizar as suas dificuldades, conforme se observa nos relatos de Marisa e Nádia: 


\begin{abstract}
[...] eles repetem, brincam, os professores que eu tenho pelo menos são muito atenciosos, eles conversam, pelo menos conversam, tem uma proximidade, eles falam "Marisa, se precisar de alguma coisa procura a monitoria se não entender, vai lá na minha sala". (Marisa, São Tomé e Príncipe).

Os professores, assim nenhum me falou diretamente que eu não estou conseguindo falar muito bem que eu deveria ter algumas aulas a mais para o português, ninguém me falou isso, mas eles sempre falam a gente sabe que você tem outra língua, mas está tudo bem. Eu e os professores, eles têm um pouco de consideração por exemplo as vezes eu esqueço muito de colocar o acento, as vezes esqueço e eles colocam. (Nádia, Peru) (informações verbais).
\end{abstract}

Os relatos das intercambistas da Alemanha e do México indicam que alguns professores permitiram a entrega de trabalhos em inglês e espanhol, respectivamente. Por outro lado, com os alunos que realizam todo o curso no Brasil, esta mesma facilidade não foi permitida, como se observa no relato de Lívia analisado anteriormente. 0 pressuposto é o domínio da fala e da escrita acadêmica em língua portuguesa, uma vez que receberão, em casos de mobilidade de grau, um diploma de instituição brasileira. Essa exigência é explícita nos documentos que regulamentam o PEC-G. Além disso, os estudantes desse convênio não podem ser reprovados mais de uma vez nas disciplinas sob pena de perder a vaga e terem de retornar aos seus países (BRASIL, 2013a, 2013b).

Em síntese, observamos nesse conjunto de estratégias que grande parte dos estudantes $(86 \%)$ afirma pedir ajuda aos colegas brasileiros. Tal auxílio é diverso, compreendendo o compartilhamento de resumos, conversas sobre os conteúdos das disciplinas, auxílio na interpretação de textos e na elaboração de atividades indicadas pelos professores. Para esses alunos, a interação com os colegas brasileiros é uma estratégia fundamental para adquirir a fluência na língua portuguesa.

Outros $78 \%$ usam a escrita de resumos dos conteúdos e dos textos e anotações em geral realizadas em língua portuguesa. É importante destacar que o gênero resumo é relatado por esses estudantes não como uma exigência dos professores, mas como uma produção de iniciativa própria que tampouco será socializada, a menos que o seja com os colegas mais íntimos, utilizada para o auxílio na compreensão dos conteúdos a serem estudados. As anotações são aquelas realizadas durante as aulas para a fixação do conteúdo, são cópias do quadro ou as impressões dos alunos sobre a fala dos professores durante as aulas ou sobre os textos indicados para leitura fora da sala de aula.

Constatamos que a metade dos estudantes realiza marcações em textos impressos. Tais marcações se referem a grifos para destaque em diferentes cores dos conceitos desconhecidos ou importantes. Há, ainda, as anotações escritas no verso dos artigos ou nos livros lidos. Algumas das estratégias se relacionam com as formas de estudo utilizadas por estudantes de pós-graduação pesquisados por Macedo (2017). Esses alunos 
utilizaram-se de marcações para o destaque de alguns termos ou ideias (utilizando o Google para pesquisa de conceitos desconhecidos) e a escrita, por meio dos fichamentos.

A leitura de livros em português também é recorrente para esses estudantes, especialmente os que se referem a conteúdos relacionados às disciplinas, indicados pelos professores para a realização de atividades ou a partir de outros interesses. Os dados indicam as perguntas realizadas aos professores como uma estratégia de compreensão nas disciplinas. Enquanto $१$ estudantes relataram contar com o auxílio de colegas brasileiros, apenas 6 indicaram perguntar aos professores em casos de dúvidas. Isso demonstra que, apesar do diálogo e de uma postura mais colaborativa de seus professores, a maioria sentese mais à vontade na interação com seus pares.

Os estudos de Marinho (2010) e Fiad (2011) demonstram que os docentes esperam que os alunos iniciem um curso universitário dominando a escrita acadêmica, já que passaram por um processo de avaliação antes do seu ingresso num curso de graduação. Para Fiad (2011, p. 362), "os letramentos dos alunos não são reconhecidos e os alunos são vistos como sujeitos iletrados pela universidade." Porém, como o modelo de Letramentos Acadêmicos é constituído por uma série de práticas sociais contextualizada, Lea e Street (1998) argumentam que não se pode esperar que estudantes entrem no ensino superior dominando os gêneros e a linguagem própria desse espaço social.

Os gêneros acadêmicos são requeridos no ensino superior sem maiores esclarecimentos sobre a sua elaboração, sem que suas características, seus modos de escrita e de circulação sejam explicitados aos alunos, configurando-se no que Lilis (1999) nomeou como práticas institucionais do mistério. Assim, é comum, conforme relata Joaquim, a necessidade de que "a ficha caia", não apenas pela mudança de país, mas também pela diferença percebida nas atividades demandadas no ensino superior, em comparação a outros níveis de ensino. Por outro lado, não nos parece, no caso aqui analisado, que essa tem sido a postura dos professores em relação a constituição de letramentos acadêmicos desses estudantes estrangeiros.

Nesse sentido, constatamos que os estudantes desenvolvem estratégias, em sua maioria, mediante experiências pessoais, pelo intermédio de professores, dos colegas e da instituição, quando as dificuldades se tornam mais evidentes. Tais estratégias têm como finalidade o atendimento das demandas e um uso mais adequado da língua portuguesa falada e escrita no contexto acadêmico. 


\section{CONSIDERAÇÕES FINAIS}

Os dados aqui analisados indicam que os estrangeiros buscam desenvolver um habitus acadêmico, utilizando-se de estratégias para uma melhor participação nas aulas, para serem bem-sucedidos nas avaliações, na apresentação de seminários e na interlocução com os colegas e professores, visando a alcançar sucesso na realização da graduação. Como se pode notar, a língua portuguesa oral e escrita tem papel preponderante na formação desses sujeitos, possibilitando a sistematização do conhecimento formal e a apropriação da linguagem própria do ambiente acadêmico.

A diversidade de práticas de letramentos acadêmicos presentes nas estratégias utilizadas, tais como o registro em áudio, escrito e visual das aulas, por meio de gravações, anotações e fotografias, respectivamente, parece contribuir de forma efetiva para o avanço na apropriação da linguagem acadêmica. Todos esses elementos são, portanto, constitutivos dos letramentos acadêmicos praticados no ensino superior, por meio de diversos gêneros tanto orais quanto escritos. Assim, essa apropriação se dá por meio de múltiplas formas, oral, escrita, audiovisual, tornando-se um fenômeno diverso e plural.

Observa-se o uso da língua materna como apoio nesse processo, sendo utilizada nas anotações da aula (o caso de Suzan), na interação com os próprios conterrâneos e até mesmo com os brasileiros, que se dispõem a interagir em espanhol, como relatado por Lívia. Diferentemente do que foi evidenciado por Macedo e Barroso (2010), a utilização do idioma crioulo pelos cabo-verdianos no contexto universitário não foi por nós percebida. Isto se dá, provavelmente, pela ausência de mais de um estudante falante de crioulo numa mesma sala de aula. Porém, para os latino-americanos, a utilização do espanhol é recorrente, em grupo, dentro e fora da universidade, e na entrega das atividades em seu idioma, quando se trata de estudantes intercambistas.

Esperamos que este artigo contribua, de forma efetiva, com as reflexões sobre o Campo de Letramentos Acadêmicos e as relações de poder constitutivas do Campo Científico, que não se restringem à escrita de gêneros acadêmicos, mas à utilização da língua na sua diversidade e a consequente necessidade de os estudantes desenvolverem estratégias para lidarem com essa diversidade e serem bem-sucedidos. Nossos dados questionam acerca da falta, nas instituições de um modo geral, de estratégias de integração mais efetivas, que dizem respeito à preparação dos professores, de atividades extracurriculares, adequação de espaços como a biblioteca, planejamento de avaliações, oferta de tutores aos alunos, dentre outras.

Em última instância, cabe a compreensão acerca de como nosso país têm se desenvolvido em suas políticas para a internacionalização, no que diz respeito à recepção de estudantes estrangeiros em nossas universidades. Os cursos de português como língua 
estrangeira têm sido incluídos nas instituições, contudo, ainda existem poucas pesquisas que nos auxiliem a melhor compreender o caso brasileiro, um país que somente na última década despertou para a formulação de políticas de internacionalização de suas instituições de ensino, para sua produção científica e para políticas linguísticas de difusão do seu idioma.

\section{REFERÊNCIAS}

AZEVEDO, M.; SLVA-JÚNIOR, J. dos R.; CARANI, A. M. A internacionalização da educação superior em diálogos: circulação de ideias, bem público e imperialismo cultural. In: SILVA-JUNIOR, J. dos R. et al. (org.). Educação superior: internacionalização, mercantilização e repercussões em um campo de disputas. Belo Horizonte: Fino Traço, 2015. v. 1, p. 49-67.

BAGNO, M. Preconceito Linguístico o que é, como se faz. São Paulo: Edições Loyola, 2007.

BAKHTIN, M. Marxismo e filosofia da linguagem. 7. ed. São Paulo: Hucitec, 1929/1995.

BARTON, D.; HAMLTON, M.; IVANIC, R. (org.). Situated literacies: reading and writing in context. London: Routledge, 2000.

BOURDIEU, P. Compreender. In: BOURDIEU, P. (org.). A miséria do mundo. 6. ed. Petrópolis: Vozes, 2007. p. 693-732.

BOURDIEU, P. Da regra às estratégias. In: BOURDIEU, P. Coisas ditas. São Paulo: Brasiliense, 2004.

BOURDIEU, P. Escritos de Educação. Organizado por M. A. Nogueira e A. Catani. Petrópolis: Vozes, 2008. (Ciências Sociais da Educação).

BOURDIEU, P. 0 Campo Científico. In: ORTIZ, R. (org.). Pierre Bourdieu: sociologia. São Paulo: Ática, 1983. (Grandes Cientistas Sociais, n. 39).

BOURDIEU, P. 0 poder simbólico. Rio de Janeiro: Bertrand Brasil, 1989.

BOURDIEU, P. Razões práticas: sobre a teoria da ação. Campinas, SP: Papirus, 1996.

BRASIL. Decreto n. 7.948, de 12 de mar. de 2013. Dispõe sobre o Programa de Estudantes-Convênio de Graduação - PEC-G. Diário Oficial da União, Brasília, DF, 2013a. Disponível em: http://www.planalto.gov. br/ccivil_03/_ato2011-2014/2013/decreto/d7948.htm. Acesso em: १३ jun. 2020.

BRASIL. Ministério da Educação. Manual do Programa de Estudantes-Convênio de Graduação PEC-G. Diário Oficial da União, Brasília, DF, 13 mar. 2013b. Disponível em: http://www.dce.mre.gov.br/PEC/G/ docs/Manual_do_Estudante-Convenio_PT.pdf. Acesso em: 13 jun. 2020.

DIAS, F. C. Mineiridade: construção e significado atual. Ciência \& Trópico, v. 13, n. 1, 2011. Disponível em: https://periodicos.fundaj.gov.br/CIC/article/view/375. Acesso em: 14 dez. 2020. 
FARACO, C. A. Norma culta brasileira: construção e ensino. In: ZILLES, A. M. S.; FARACO, C. A. (org.). Pedagogia da Variação Linguística língua, diversidade e ensino. São Paulo: Parábola Editoria, 2015.

FIAD, R. S. A escrita na universidade. Revista da ABRALIN, v. 10, n. 4, p. 357-369, 2011. Disponível em: http://ojs.ufgd.edu.br/index.php/Raido/article/view/5688. Acesso em: १३ jun. 2020.

FIAD, R. S. Algumas considerações sobre os letramentos acadêmicos no Brasil. Pensares em Revista, n. 6, p. 23-34, 2015. Disponivel em: https://www.e-publicacoes.uerj.br/index.php/pensaresemrevista/ article/view/18424. Acesso em: 13 jun. 2020.

FISCHER, A. Práticas de Letramento acadêmico em um curso de Engenharia Têxtil: o caso dos relatórios e suas dimensões escondidas. SCRIPTA, v. 15, n. 28, p. 37-58, 2011. Disponível em: http://periodicos. pucminas.br/index.php/scripta/article/view/4298. Acesso em: 2 dez. 2017.

GONÇALVES, S. Internacionalização em casa: a experiência da ESEC. Exedra, v. 1, 2009. Disponível em: https://dialnet.unirioja.es/descarga/articulo/3398339.pdf. Acesso em: १३ jun. 2020.

LEA, M. R.; STREET, B. V. Student writing in higher education: an academic literacies approach. Studies in Higher Education, v. 23, n. 2, p. 157-16, 1998. Disponivel em: https://www.tandfonline.com/doi/abs/10. 1080/03075079812331380364. Acesso em: 13 jun. 2020.

LILLIS, T. Whose common sense? Essayist literacy and the institutional practice of mystery. In: JONES, C; TURNER, J.; STREET, B. (org.). Student writing in university: cultural and epistemological issues. Amsterdam: John Benjamins, 1999. p. 127-147.

LILLIS, T.; SCOTT, M. Defining academic literacies research: issues of epistemology, ideology and strategy. Journal of Applied Linguistics, v. 4, n. 1, p. 5-32, 2007.

LILLIS, T. Student writing: access, regulation, desire. London: Routledge, 2001.

MACEDO, M. do S. A. N.; BARROSO, N. P. Práticas de letramento acadêmico de estudantes-convênio de graduação: uma análise das relações entre língua e identidade. Revista Brasileira de Estudos Pedagógicos, v. 91. n. 229, p. 604-621, 2010. Disponível em: http://rbepold.inep.gov.br/index.php/rbep/ artiqcle/view/632/612. Acesso em: 13 jun. 2020.

MACEDO, M. do S. A. N.; NEVES-JÚNIOR, B. Práticas de letramento acadêmico em um curso de Geografia. Revista Brasileira de Estudos Pedagógicos, v. 97, n. 245, p. 68-81, 2016. Disponível em: https://www. scielo.br/scielo.php?pid=S2176-66812016000100068\&script=sci_abstract\&tlng=pt. Acesso em: 13 jun. 2020.

MACEDO, M. do S. A. N. Letramento acadêmico como uma prática dialógica: contribuições de Bakhtin. In: FREITAS, M. T. de A.; RAMOS, B. S. da S. (org.). Bakhtin Partilhado. 1. ed. Curitiba: CRV, 2017. p. 47-56. 
MARINHO, M. A escrita nas práticas de letramento acadêmico. Revista Brasileira de Linguística Aplicada, v. 10, n. 2, 2010, p. 363-386. Disponivel em: https://www.scielo.br/scielo.php?script=sci_arttext\&pid $=$ S1984-63982010000200005. Acesso em: 13 jun. 2020.

MIGNOLO, W.; CARBALLO, F. Una concepción descolonial del mundo: conversaciones entre Francisco Carballo y Walter Mignolo. Buenos Aires: Educaciones del Signo, 2014. Disponível em: https://revistas. unc.edu.ar/index.php/cardi/article/view/17504. Acesso em: 13 jun. 2020.

MIRANDA, J. A. A. de; STALLIVIERI, L. Para uma Política de internacionalização para o ensino superior no Brasil. Avaliação, v. 22, n. 3, p. 589-613, nov. 2017. Disponível em: http://www.scielo.br/scielo. php?pid=S1414-40772017000300589\&script=sci_abstract\&tlng=pt. Acesso em: 20 maio 2018.

MOROSINI, M. C.; NASCIMENTO, L. M. de. Internacionalização da Educação Superior no Brasil: a produção recente em teses e dissertações. Educação em Revista, n. 33, p. 1-27, 2017. Disponivel em: http:// www.scielo.br/scielo.php?pid=S0102-46982017000100109\&script=sci_abstract\&tlng=pt. Acesso em: 20 maio 2018.

NOGUEIRA, M. A.; NOGUEIRA, C. M. M. Bourdieu e a Educação. Belo Horizonte: Autêntica, 2004. v. 4.

PERES, E. P. 0 uso de você, ocê e cê em belo horizonte: um estudo em tempo aparente e em tempo real. 2006. Tese (Doutorado em Letras) - Universidade Federal de Minas Gerais, Belo Horizonte, 2006.

PRENSKY, M. Nativos digitais, imigrantes digitais. De On the Horizon, v. 9, n. 5, out. 2001. Disponível em: http://www.colegiongeracao.com.br/novageracao/2_intencoes/nativos.pdf. Acesso em: 13 jun. 2020.

RIBEIRO, P. R. 0.; SOARES, M. S.; LACERDA, P. F. A. da C. A realização da noção de existência no "mineirês": um estudo da variação dos verbos ter, haver e existir. Signótica, v. 25, n. 2, p. 535-561, jul./dez. 2013.

SANTOS, P. A. D. G. C. Letramento acadêmico e estratégias de estudantes estrangeiros da UFSJ. 2019. Dissertação (Mestrado em Educação) - Universidade Federal de São João del Rei, São João del Rei, 2019.

STREET, B. Literacy in theory and practice. Cambridge: Cambridge University Press, 1984.

Endereço para correspondência: Praça Frei Orlando, 170, Centro, 36307-352, São João del-Rei, Minas Gerais, Brasil; socorronunes@ufsj.edu.br 
